PPPL-3467

UC-70

\title{
Precision Metrology of NSTX Surfaces Using Coherent Laser Radar Ranging
}

by

H.W. Kugel, D. Loesser, A.L. Roquemore, M.M. Menon, and R.E. Berry

July 2000

$\int D \sqrt{D} \int \sqrt{\zeta} \int\left[\begin{array}{l}\text { PAINCETON } \\ \text { PLABMA PHYSICS } \\ \text { LABOAATOAY }\end{array}\right.$

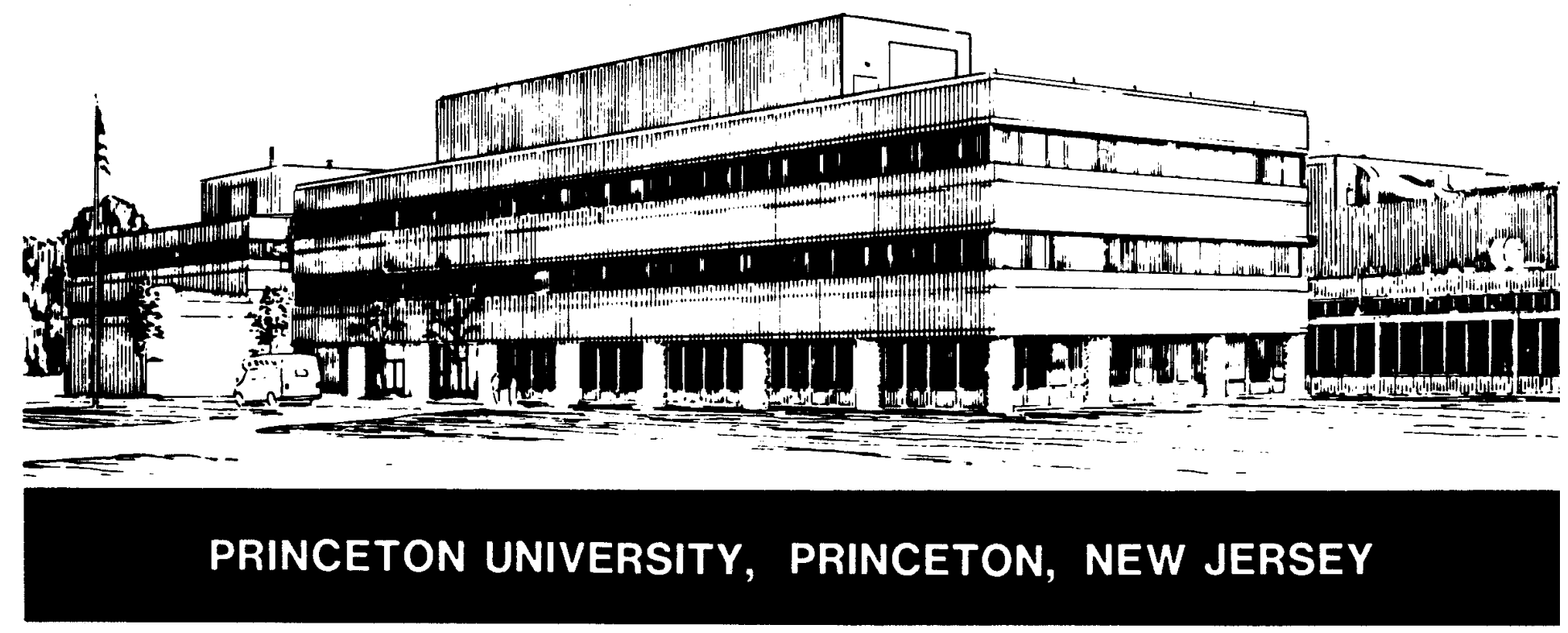




\section{PPPL Reports Disclaimer}

This report was prepared as an account of work sponsored by an agency of the United States Government. Neither the United States Government nor any agency thereof, nor any of their employees, makes any warranty, express or implied, or assumes any legal liability or responsibility for the accuracy, completeness, or usefulness of any information, apparatus, product, or process disclosed, or represents that its use would not infringe privately owned rights. Reference herein to any specific commercial product, process, or service by trade name, trademark, manufacturer, or otherwise, does not necessarily constitute or imply its endorsement, recommendation, or favoring by the United States Government or any agency thereof. The views and opinions of authors expressed herein do not necessarily state or reflect those of the United States Government or any agency thereof.

\section{Availability}

This report is posted on the U.S. Department of Energy's Princeton Plasma Physics Laboratory Publications and Reports web site in Calendar Year 2000. The home page for PPPL Reports and Publications is: http://www.pppl.gov/pub_report/

DOE and DOE Contractors can obtain copies of this report from:

U.S. Department of Energy

Office of Scientific and Technical Information

DOE Technical Information Services (DTIS)

P.O. Box 62

Oak Ridge, TN 37831

Telephone: (865) 576-8401

Fax: (865) 576-5728

Email: reports@adonis.osti.gov

This report is available to the general public from:

National Technical Information Service

U.S. Department of Commerce

5285 Port Royal Road

Springfield, VA 22161

Telephone: $1-800-553-6847$ or

(703) $605-6000$

Fax: (703) 321-8547

Internet: http://www.ntis.gov/ordering.htm 


\title{
Precision Metrology of NSTX Surfaces Using Coherent Laser Radar Ranging
}

\author{
H.W. Kugel, D. Loesser, A. L. Roquemore \\ Princeton Plasma Physics Laboratory, Princeton, NJ 08543, USA
}

M. M. Menon and R. E. Barry

Oak Ridge National Laboratory, Oak Ridge TN, 37831, USA

\begin{abstract}
A frequency modulated Coherent Laser Radar ranging diagnostic is being used on the National Spherical Torus Experiment (NSTX) for precision metrology. The distance (range) between the $1.5 \mu \mathrm{m}$ laser source and the target is measured by the shift in frequency of the linearly modulated beam reflected off the target. The range can be measured to a precision of $<100 \mu \mathrm{m}$ at distances of up to 22 meters. A description is given of the geometry and procedure for measuring NSTX interior and exterior surfaces during open vessel conditions, and the results of measurements are elaborated.
\end{abstract}

\section{INTRODUCTION}

NSTX is the first step in an investigation of the physics principles of low-aspectratio Spherical Tori (ST) designed to study non-inductive start-up, current sustainment and profile control, confinement and transport, pressure limits and self driven currents, stability and disruption resilience, and unique scrape-off layer (SOL) and Divertor characteristics.[1,2] These ST principles will be studied in regimes with high temperature, high density, non-inductively sustained high- $\beta_{T}$ discharges $(\simeq 40 \%)$ with high pressure driven current fractions $(\simeq 70 \%)$ which provide possible approaches toward a small, economical, high power ST reactor core.[2] In February 1999, NSTX achieved first plasma. In the first extended period of experiments, it promptly achieved high plasma current, in inner wall limited, double null, and single null plasma configurations. $130 \mathrm{kA}$ of initial non inductive current generation using $20 \mathrm{kA}$ of Coaxial 
Helicity Injection $(\mathrm{CHI})$ current has been demonstrated, and indications of electron heating with $2 \mathrm{MW}$ of High Harmonic Fast Wave RF heating (HHFW) have been obtained.[3] As expected, discharge reproducibility and performance were strongly affected by wall conditions. Some of these plasma surface interactions (PSI) might be reduced by precision alignment of plasma facing surfaces relative to the plasma boundary. PSI interactions due to misalignments, motion, damage, or erosion can complicate physics analysis and is a significant factor preventing prompt access to high performance regimes. Reducing or eliminating these effects is non-trivial in devices with complex magnetic geometries. In this paper, we describe initial procedures and results of precision metrology on NSTX PFC's, using a frequency modulated (FM) coherent laser radar (CLR) ranging diagnostic in concert with a Mechanical Measuring Arm (MMA) to establish a database for future design and analysis decisions.

\section{EXPERIMENTAL GEOMETRY}

Fig. 1 shows a partial schematic cross section of NSTX. The device capabilities include $\mathrm{R}_{0} \leq 0.85 \mathrm{~m}, \mathrm{a} \leq 0.67 \mathrm{~m}, \mathrm{R} / \mathrm{a} \geq 1.26, \kappa \leq 2.2, \delta<0.5, \mathrm{I}_{\mathrm{p}} \leq 1 \mathrm{MA}, \mathrm{B}_{\mathrm{T}} \leq 0.3 \mathrm{~T}$, and 5 sec maximum pulse length, copper Passive Stabilizer Plates, graphite power handling surfaces, $5 \mathrm{MW}$ of Neutral Beam heating (Oct. 2000), $6 \mathrm{MW}$ of $30 \mathrm{MHz}$ High Harmonic Fast Wave (HHFW) for heating and current drive at 10-20 $\omega_{\text {ICRF. }}$. The $0.2 \mathrm{~m}$ radius Center Column is clad with alternating vertical columns of $1.3 \mathrm{~cm}$ thick graphite (Union Carbide, Type ATJ) tiles between columns of 2-D Carbon Fiber Composite (CFC) (Allied Signal, Type 865-19-4) tiles. The Inner Divertor tiles are $5.1 \mathrm{~cm}$ thick graphite; the Outer Divertor and Passive Stabilizer Plate tiles are $2.5 \mathrm{~cm}$ thick graphite. Shown in Fig. 1 is a unique feature of NSTX: toroidal ceramic insulators, in the top and bottom Divertor gaps, which allows for electrical biasing of the inner and outer vessel for Coaxial Helicity Injection ( $\mathrm{CHI}$ ). This configuration enables experiments with Ohmic, Neutral Beam and HHFW heated discharges on wall limiter start-up plasmas, lower single-null diverted plasmas, and double null diverted plasmas with and without $\mathrm{CHI}$. 
During the construction and initial operating phase of NSTX, the resulting position tolerances in the mounting of actual as-built edge components ranged from about $\pm 0.25 \mathrm{~mm}$ in the Center Column region to about $\pm 0.7 \mathrm{~cm}$ in the outer region of the Passive Stabilizer and RF Antenna. The required geometrical precision will likely increase as the experimental program progresses. At this time, it appears that the principal alignment issues will include the symmetric placement of the Passive Stabilizer and the RF Antenna relative to the plasma edge to within $\pm 0.3 \mathrm{~cm}$, the alignment of graphite tiles on power handling surfaces to within $\pm 0.08 \mathrm{~mm}$, and locating edge diagnostics relative to the plasma edge to within $\pm 0.16 \mathrm{~cm}$.

\section{INITIAL INSTALLATION AND ALIGNMENT METROLOGY}

The initial NSTX in-vessel measurements were performed during the construction phase prior to installation of the Center Column. The MMA [4] was mounted on a post on the centerline of the bare vessel. This allowed MMA measurements within a $3.658 \mathrm{~m}$ spherical diameter to within an accuracy of $+/$ $0.178 \mathrm{~mm}$. Six Vessel wall monuments were mounted above and below the vessel midplane to provide permanent reference points. Each monument consisted of a Type304 Stainless steel-cylinder, $1.27 \mathrm{~cm}$ diameter by $2.54 \mathrm{~cm}$ long, and was welded into a hole bored through the vessel wall, so as to protrude into and out of the vessel at a given location. Each end of the monument had a machined indentation to provide a reference point for the MMA tip. The MMA tip consisted of a $0.318 \mathrm{~cm}$ ball probe which was moved to touch at least any 3 of the 6 monuments. The MMA software then triangulated an origin based on these reference monuments, and all subsequent measurements were referenced to this reference origin, and then translated to the coordinate system with the machine center as the origin. After the reference origin was established, the MMA was used to determine the positioning of the 48 Passive Stabilizer Plate mounting brackets, the RF Antenna, the Neutral Beam Armor, and invessel diagnostics. After the Center Column was inserted into the vessel, additional MMA measurements were made by mounting the MMA to the wall at selected locations and locating the MMA position relative to the wall monuments. The MMA measurements consisted of discrete points made at the edges or across the objects 
being measured. A best fitting geometry was then selected to render the data visual and to allow the projection of points of interest. Fig.2, for example, shows a visualization of MMA results for the "as-built" NSTX vessel port locations. This visualization is based on a table that provides the Major Radius and toroidal angle of the respective port centers, and the angular deviation of the port from a vertical plane (tilt).

\section{COHERENT LASER RADAR METROLOGY}

The MMA was found to be a very useful for in-vessel measurements while the vessel was vented for construction and maintenance. The MMA cannot be used for interior measurements while the vessel is under vacuum. In principle, the exterior side of each of the reference wall monuments could be used for exterior measurements while the vessel is under vacuum. In practice, various midplane hardware interferences around the vessel prevent the arm of the MMA from reaching very far from a particular vessel wall monument.

In order to compliment the MMA capabilities, a prototype Frequency Modulated (FM) Coherent Laser Radar (CLR) [5,6] has been applied in NSTX for remote metrology, and erosion measurements. In the FM CLR, a linear frequency modulation is applied to a laser beam $(\lambda=1.5 \mu \mathrm{m})$ and the range is proportional to the frequency shift during the round-trip transit time. The coherent light waves are combined in an optical mixer to produce a beat frequency equal to the difference frequency, i.e., the frequency change during the transit time. In laboratory tests, a prototype CLR has demonstrated the ability to perform high precision remote measurements at long ranges ( $<100 \mu \mathrm{m}$ precision for ranges up to $22 \mathrm{~m}$ ). In the present embodiment, the minimum range capability is about $1.8 \mathrm{~m}$. CLR range measurements have been found to be largely insensitive to surface reflectance characteristics and accurate over a wide range of incident angles $\left( \pm 85^{\circ}\right)$. The associated analysis software allows range coordinates measured relative to precision markers to be transferred to the machine center based coordinate system, and to generate detailed maps of surface changes 
(e.g., blistering [7]). The present CLR prototype weighs about $36 \mathrm{Kg}$ and is mounted in a cylindrical column about $0.81 \mathrm{~m}$ high by $0.23 \mathrm{~m}$ in diameter (the laser beam exits about $0.74 \mathrm{~m}$ from the base). The scanning mechanisms of the present embodiment cannot be operated while in magnetic fields greater than a few gauss.

\section{NSTX METROLOGY USING COHERENT LASER RADAR}

The During the NSTX 1999 vent, the Center Column was removed from the vessel for maintenance and positioned vertically on the concrete ground floor in the Test Cell next to NSTX. Visual inspection of the Center Column indicated that alternating columns of 2-D CFC tiles (refer to Sec.I) exhibited from 2 to 8 horizontal fracture tracks per tile, while the graphite tiles did not. These tracks have the visual appearance of cracks but were actually shallow tracks (about $0.1 \mathrm{~cm}$ wide by $0.01 \mathrm{~cm}$ to $0.1 \mathrm{~cm}$ deep and varying in length from about $0.5 \mathrm{~cm}$ to $3 \mathrm{~cm}$ ). Some tracks are uniformly deep, others appear to be a series of pits. The axises of these fracture tracks seem parallel to the carbon fibers embedded in the CFC material. Indeed the tiles were machined so that the CFC fibers were oriented parallel to the plasma facing side. However, due to the curvature of the tile surface, fiber ends appeared at the surface. These exposed ends of near surface fibers may have accelerated the erosion of fibers. A laser scan was made across one of these fracture tracks while the tile was mounted on the Center Column in order to determine the possibility of using a particular fracture track as an erosion marker during plasma operations. The initial measurements consisted of positioning the CLR on the NSTX Personnel Platform about 3m above the concrete ground floor at a distance of about $7 \mathrm{~m}$ from the Center Column and at a level below its midplane. This CLR position was unsatisfactory because the measured range data was broadened by small vibrations of the Personnel Platform and could not be used to obtain a sufficiently high resolution image of the scanned track. The CLR was then positioned firmly on the concrete floor of the Test Cell at an angle of about $45^{\circ}$ upward for a rescan of the selected fracture track region. The stability of the new position immediately improved the signal-to-noise ratio by a factor of $\sim 4 \mathrm{x}$ and resulted in the fracture track image shown in Fig.3 and Fig.4. In the case of a typical fracture track size of $0.5 \mathrm{~cm}$ long by $0.1 \mathrm{~cm}$ wide by $0.01 \mathrm{~cm}$ deep, a typical track volume of 
$\sim 5 \times 10^{-4} \mathrm{~cm}^{3}$ would have released about $1 \mathrm{mg}$, or $5 \times 10^{19}$ atoms of carbon into the plasma edge, which is a significant carbon source. This CFC behavior will be monitored during forthcoming high power Neutral Beam operations by attempting to scan the same or similar tracks through a midplane quartz window on NSTX. The same window can be used to measure PFC displacements and motion under vacuum conditions.

CLR scans of the interior of NSTX were performed by mounting the scanner unit at the edge of vessel ports. High precision $(1.2700 \mathrm{~cm}$ diameter) stainless steel ball bearings were mounted on the wall monuments used for the MMA measurements. The exact positions of these reference targets were measured from the CLR location, and by using the MMA calibration, all the CLR data collected from that location could be transferred to the machine center based coordinate system. Fig.5 shows range data measured from Bay- $A$ and Bay-K ports on plasma facing surfaces which are transferred to the machine center based coordinate system to render this image. Five toroidal line scans along the RF antenna front surface are also superimposed. Fig.6. shows a range-based image of the plasma facing surfaces of NSTX (partially assembled). Here, the passive plate assembly uniformity is highlighted by coloring the radial range data within a band of $1.32-1.35 \mathrm{~m}$. Shown are features of the Center Column, the Passive Plate structures, the RF Antenna, the Lower Divertor, and Neutral Beam Armor. The tabular data used to generate this visual image can be used to design the shims needed to adjust near edge elements, such as Passive Stabilizer plates.

Remote measurements were performed from a distance of about $19 \mathrm{~m}$ of the northward side of the exterior of the vessel when some northward ports were open, thus allowing the external Toroidal Field (TF) coils to be measured relative to internal hardware such as the Center Column. These measurements used similar ball bearing monuments mounted on wall of the Test Cell. 
In laboratory tests, using a series of Doppler corrected range measurements, the CLR has been used measure small target (audio speaker) vibration frequencies $\quad<10$ $\mathrm{Hz}$ ). These capabilities suggest that the motion of plasma facing components (PFC) can be measured during plasma current disruptions. Using such measurements, the forces acting on PFCs during a disruption event could be estimated from the measured displacement. The limits of motion (amplitude and frequency) that can be presently measured are limited by signal broadening and the bandwidth limits of the CLR signal processor.

\section{CONCUSIONS}

The initial CLR measurements of NSTX have demonstrated this to be a very powerful technique for measuring and comparing the precise location and surface features of components measured in air with those measurements performed under vacuum conditions and at high temperatures. In addition, the CLR ability to scan from remote locations allows measuring the position of large external engineering components, such as magnetic coils, relative to internal components. A new compact design concept of the CLR, capable of operating in vacuum condition, has been completed. This will significantly improve the usefulness of the CLR for fusion applications.

\section{ACKNOWLEDGMENTS}

This work is supported by U. S. DoE Contracts DE-AC02-76CH03073 and DEAC05-00R22725.

\section{REFERENCES}

1. Y-K. M. Peng and D. Strickler, Nucl. Fusion, 26, (1986) 769.

2. S.M. Kaye, et al., Fus. Technol. 36, (1999) 16, and references therein.

3. M. Bell, et al., to appear in Proc. of the European Physical Society Conference on Controlled Fusion and Plasma Physics, Budapest, Hungary, June 12-16, 2000.

4. Faro Technologies Inc., 125 Technology Park, Lake Mary, Florida, 32746, Model 12 Ft., Silver Series, 2-2-3, Turnkey System. 
5. Metric Vision (formerly Coleman Research Corp.), 8500 Cinder Bed Road, Suite 15, Newington, VA 22122.

6. P.T. Spampinato, et al., in Proc. of 17th IEEE/NPSS Symp. on Fusion Engineering, 6-10 October, 1997, San Diego CA, and references therein.

7. C.H. Skinner, et al., to appear in Proc. of 14th Int. Conf. on Plasma Surface Interactions in Controlled Fusion Devices, Rosenheim, Germany, May22-26,2000.

\section{FIGURE CAPTIONS}

Fig.1. Partial schematic cross section of the NSTX device.

Fig.2. Display of NSTX vessel port locations. Data points measured with Mechanical Measuring Arm (MMA), best fitted to planes and circles, and transferred to cylindrical coordinates at the plasma center a ( $R, Z$, and toroidal angle).

Fig.3. Front view of CLR scan of Center Column CFC showing fracture track and a tile mounting screw hole.

Fig.4. Side view of Fig.3 CLR scan showing track width and depth.

Fig.5. Range data measured from Bay-A and Bay-K ports on plasma facing surfaces are transferred to the machine center based coordinate system to render this image. Five toroidal line scans along the RF antenna front surface are also superimposed.

Fig.6. Range-based image of the plasma facing surfaces of NSTX (partially assembled). Here, the passive plate assembly uniformity is highlighted by coloring the radial range data within a band of $1.32-1.35 \mathrm{~m}$. 


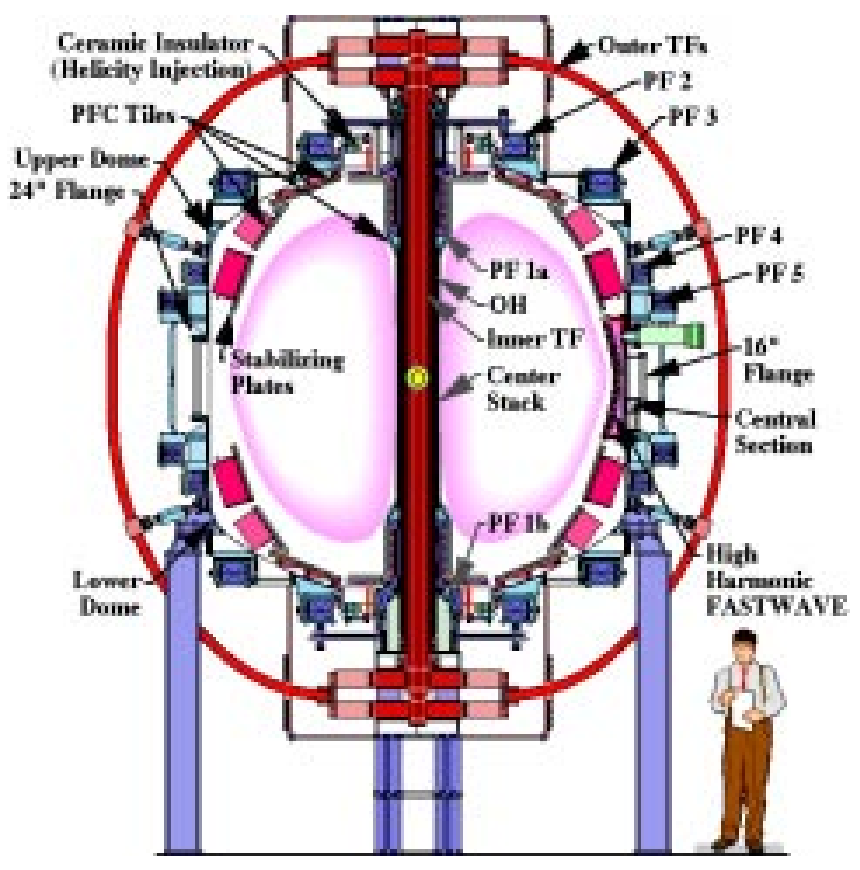

Fig.1. Partial schematic cross section of the NSTX device. 


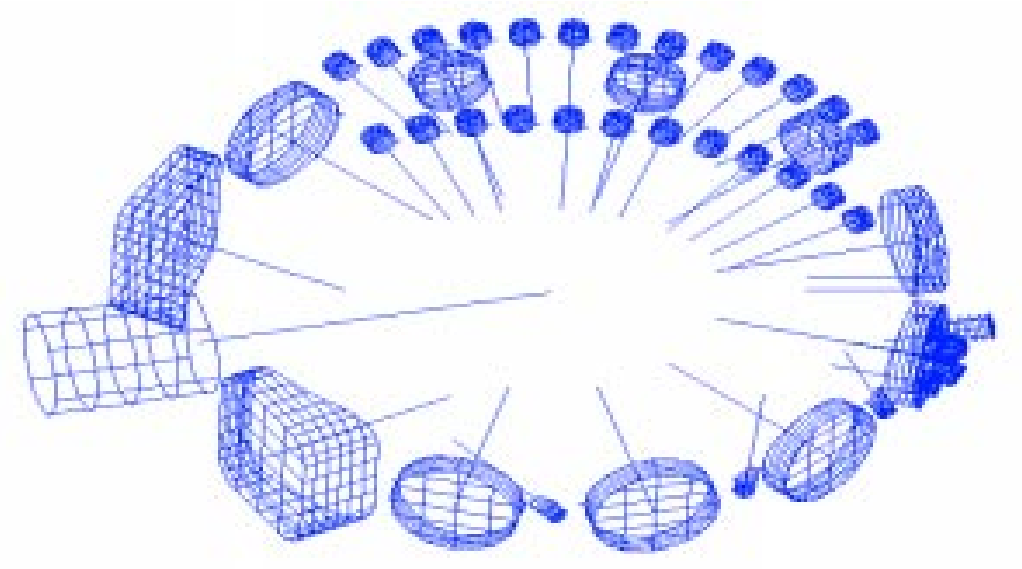

Fig.2. Display of NSTX vessel port locations. Data points measured with Mechanical Measuring Arm (MMA), best fitted to planes and circles, and transferred to cylindrical coordinates at the plasma center a ( $\mathrm{R}, \mathrm{Z}$, and toroidal angle). 


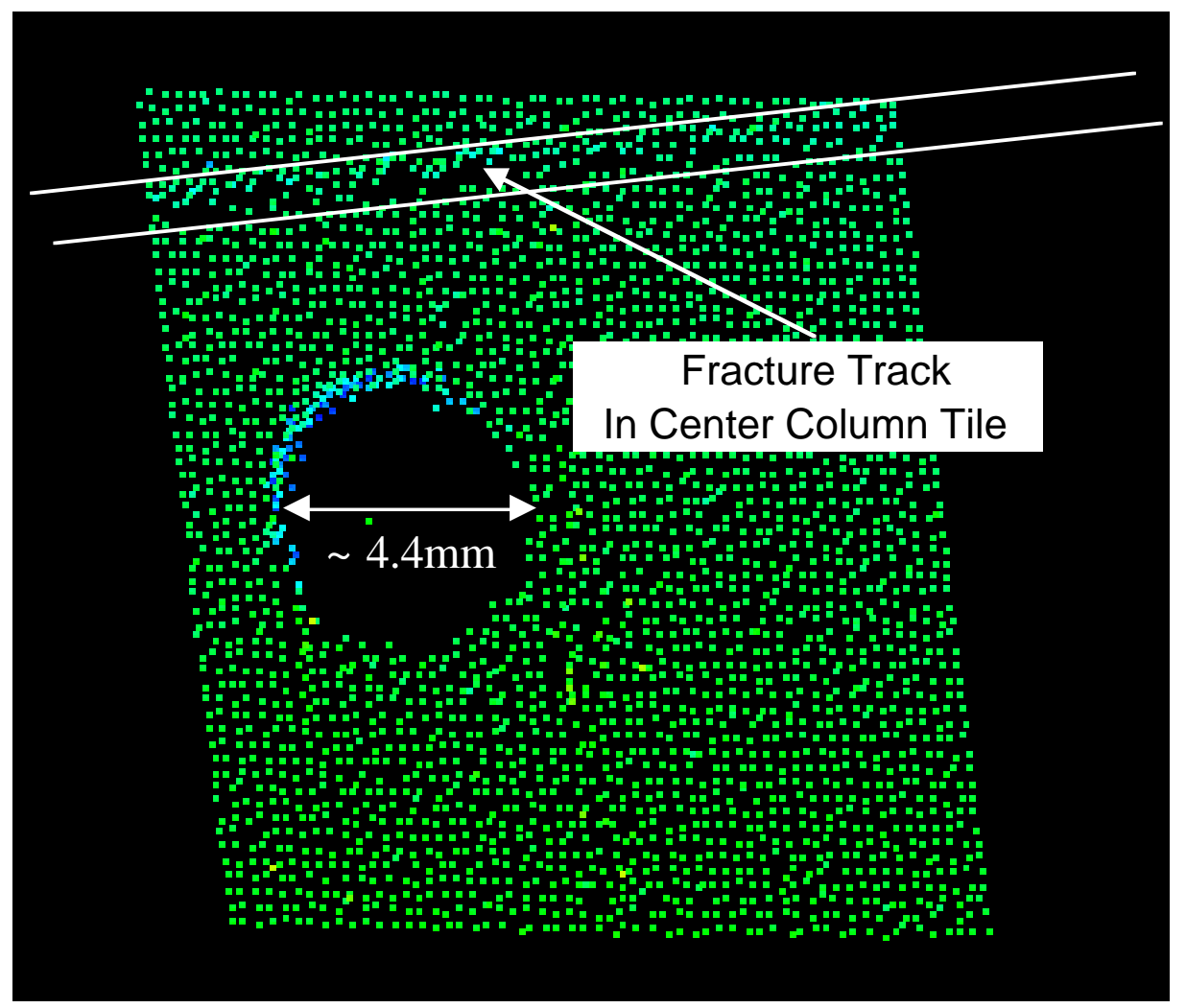

Fig.3. Front view of CLR scan of Center Column CFC showing fracture track and a tile mounting screw hole. 


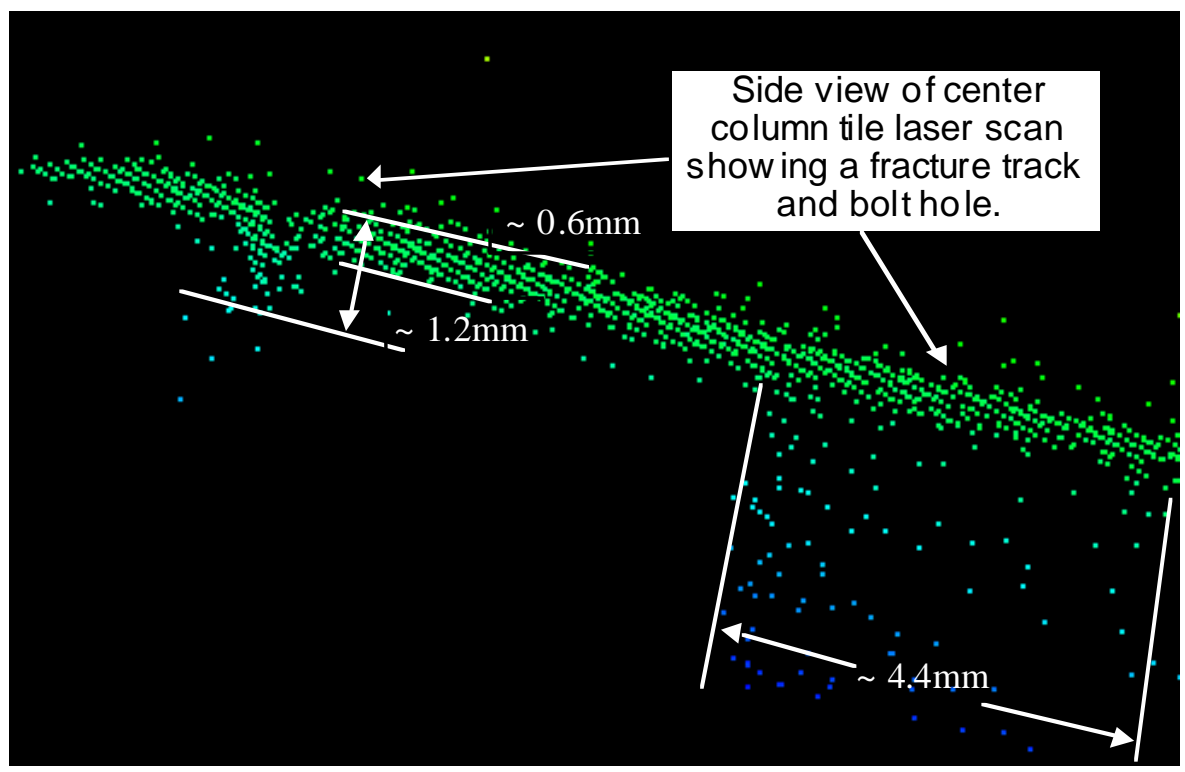

Fig.4. Side view of CLR scan (Fig.3) showing track width and depth. 


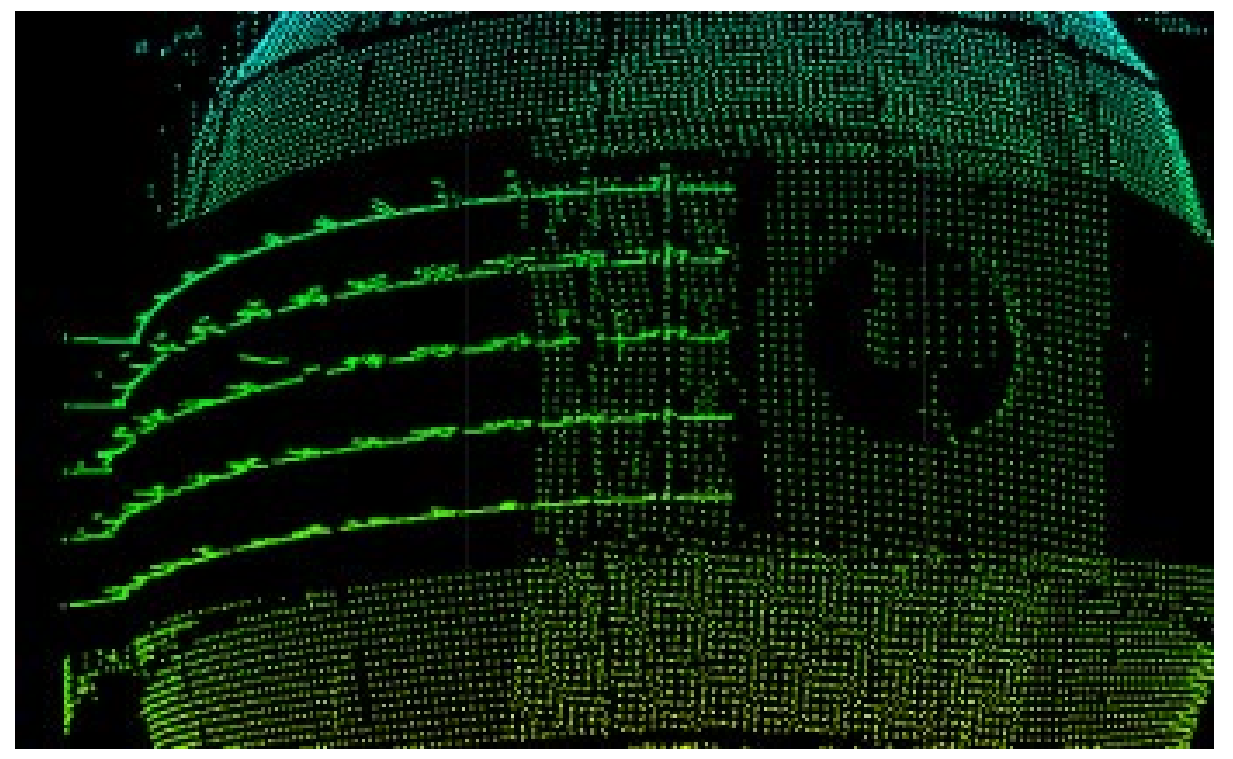

Fig.5. Range data measured from Bay-A and Bay-K ports on plasma facing surfaces are transferred to the machine center based coordinate system to render this image. Five toroidal line scans along the RF antenna front surface are also superimposed. 


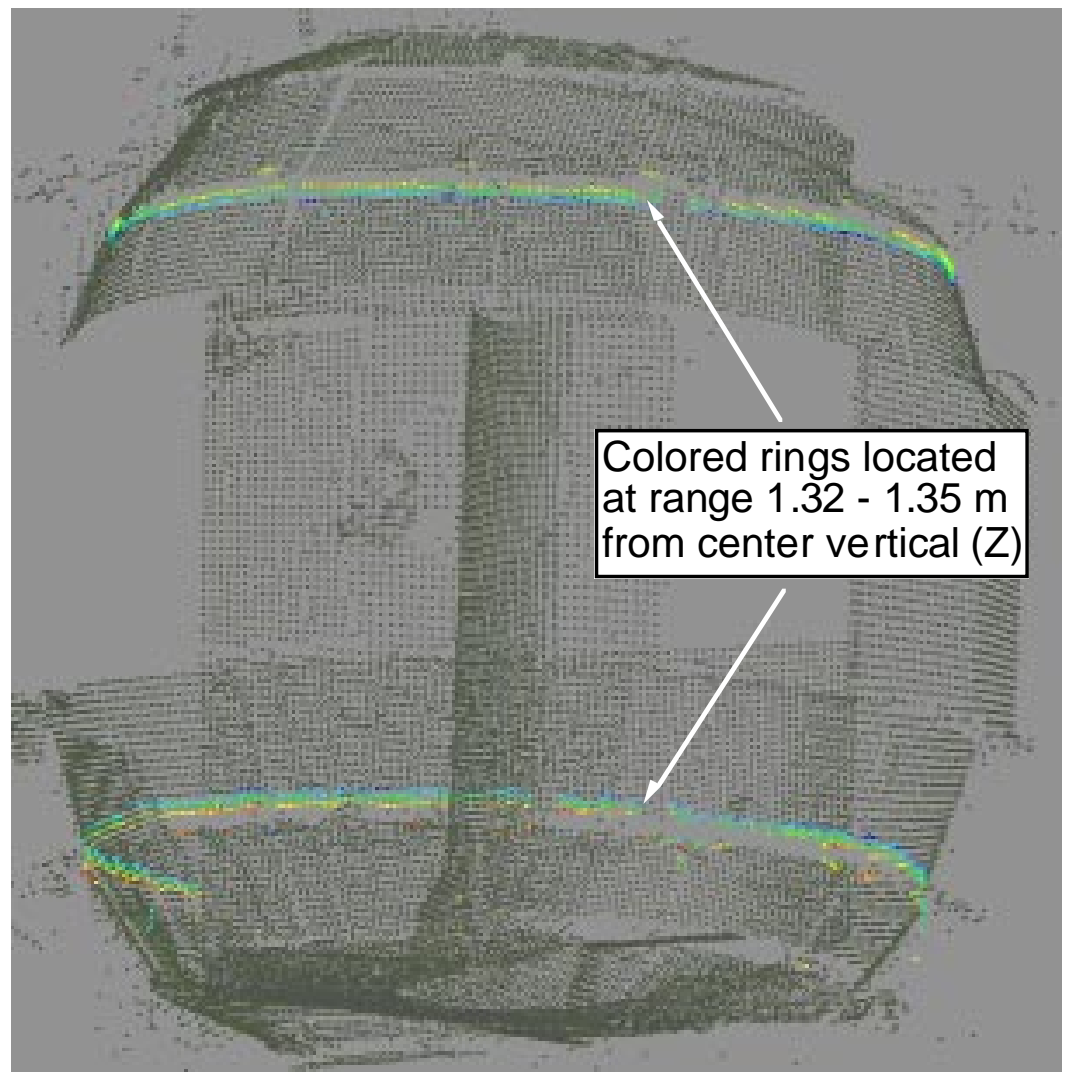

Fig.6. Range-based image of the plasma facing surfaces of NSTX (partially assembled). Here, the passive plate assembly uniformity is highlighted by coloring the radial range data within a band of $1.32-1.35 \mathrm{~m}$. 
The Princeton Plasma Physics Laboratory is operated by Princeton University under contract with the U.S. Department of Energy.

\author{
Information Services \\ Princeton Plasma Physics Laboratory \\ P.O. Box 451 \\ Princeton, NJ 08543
}

Phone: 609-243-2750

Fax: 609-243-2751

e-mail: pppl_info@pppl.gov

Internet Address: http://www.pppl.gov 